\title{
Tekirdağ' da Çorlu ilinde endüstriyel alanlardaki toprakta ağır metal kirliliğinin çevresel ve insan sağlığ açısından etkileri
}

\author{
Ayşe Handan DÖKMECí ${ }^{1, *}$, Suna Özden ÇELIK' ${ }^{2}$, \\ Gül KAYKIOĞLU², Atakan ÖNGEN ${ }^{3}$ \\ ${ }^{1}$ Namık Kemal Üniversitesi, Sağlık Yüksekokulu Acil Yardım ve Afet Yönetimi Bölümü, Tekirdağ \\ ${ }^{2}$ Namık Kemal Üniversitesi, Çorlu Mühendislik Fakültesi, Çevre Mühendisliği Bölümü, Tekirdag \\ ${ }^{3}$ Ístanbul Üniversitesi, Mühendislik Fakültesi, Çevre Mühendisliği Bölümü, Istanbul
}

Geliş Tarihi (Recived Date): 22.06.2017

Kabul Tarihi (Accepted Date): 06.10.2017

\section{Özet}

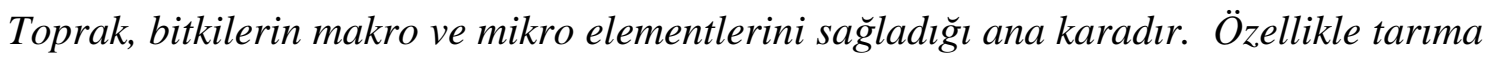
elverişli toprakların yakınında kurulan sanayi tesisleri çevresel ve insan sağlığl açısından büyük tehdit oluşturmaktadır. Tekirdăg'ın Çorlu ilçesinde bulunan sanayi tesislerinin oluşturduğu kirlilik yüzey suyunun da kalitesini etkilemiş ve bunun sonucunda toprak da etkilenmiştir. Toprak kirliliği besin zinciri yoluyla insan să̆lı̆̆ını büyük oranda etkilemektedir. Çalışmamızda 2006- 2007 yılları arasında sanayinin yoğun olduğu Çorlu ilinden 3 aylık periyotlar şeklinde toprak numuneleri toplanmıştır.Sanayi atık sularının deşarj edildiği yüzey sularına yakın 7 noktadan toplanan toprak numunelerinde $\mathrm{Pb}, \mathrm{Cu}, \mathrm{Zn}, \mathrm{Fe}, \mathrm{Mn}, \mathrm{Ni}, \mathrm{Co}, \mathrm{Cd}$ ve Cr miktarları Alevli Atomik Absorbsiyon Spektrometresi (FAAS) ile belirlenmiştir. Tespit edilen ă̆ır metal miktarlarını ulusal ve uluslararası izin verilebilir sinır değerlerle karşılaştırarak değerlendirilmiştir. Özellikle Türkgücü köyü, Çorlu deresi (Sinop Mah.) ve Velimeşe Çerkezköy Organize Sanayi Bölgesi (OSB) civarından toplanan toprak numunelerinde $\mathrm{Zn}, \mathrm{Cr}$, Cd ve Ni içeriği çoğunlukla Toprak Kirliliği Kontrol Yönetmeliği (TKKY) EKIa'da belirtilen sınır değerlerin üzerinde tespit edilmiştir. Toprakta tespit edilen ă̆ır metallerin varlığl, tarımsal üretime, yer altı suyu kalitesine ve dolayl yoldan insan sağlığına olumsuz etkide bulunabilir. Bu yüzden ă̆ır metaller tarafindan kirlenmiş topră̆ın iyileştirilmesi, pestisit kullanımının kontrolü ve en önemlisi ă̆ır metalleri giderebilecek arıtma tesislerinin dizaynını yaparak antropojenik kaynaklı atık suların arıtılarak alıcı ortamlara verilmesini sağlamaktır.

Anahtar kelimeler: Endüstriyel bölge, ăğr metal kirliliği, toprak, insan sağlı̆̆l, Tekirda ğ.

\footnotetext{
*Ayşe Hadan DÖKMECİ, hdokmeci@nku.edu.tr, http://orcid.org/0000-0002-4439-4422

Suna Özden ÇELIK, sunacelik@nku.edu.tr, http://orcid.org/0000-0001-9783-9512

Gül KAYKIOĞLU, gkaykioglu@nku.edu.tr, http://orcid.org/0000-0003-3271-211X

Atakan ÖNGEN, aongen@istanbul.edu.tr, http://orcid.org/0000-0002-9043-7382
} 


\title{
Environmental and human health effects of heavy metal pollution in the soil in industrial areas in Çorlu province in Tekirdağ
}

\begin{abstract}
Soil is the main terrain where plants provide macro and micro elements. Especially industrial facilities established near arable land poses a great threat to environment and human health. The pollution produced by the industrial facilities located in Corlu district of Tekirda $\breve{g}$ affected the quality of the surface water and as a result it was affected in the soil too. Soil pollution is influenced by the human chain of nutrients in large proportions. In our work, soil samples were collected from Corlu province between 2006 and 2007 in 3-month periods. Pb, Cu, Zn, Fe, Mn, Ni, Co, Cd and Cr were determined by Flame Atomic Absorption Spectrometry (FAAS) in soil samples collected from the surface near the surface waters where industrial wastewater was discharged. The quantities of detected heavy metals were evaluated by comparing them with national and international permissible limit values. Especially $\mathrm{Zn}, \mathrm{Cr}, \mathrm{Cd}$ and $\mathrm{Ni}$ contents in soil sampled from Türkgücü village, Corlu stream (Sinop neighborhood) and Velimeşe Çerkezköy OSB have mostly been determined above the limit values stated in TKKY Annex-Ia. The presence of heavy metals detected in the soil can negatively affect agricultural production, groundwater quality and indirect human health. Therefore, the treatment of soil polluted by heavy metals, the control of pesticide usage and the most important is to design the treatment plants which can remove heavy metals, so that the anthropogenic wastewater is treated and supplied to the receiving environments.
\end{abstract}

Keywords: Industrial district, heavy metal pollution, soil, human health, Tekirdağ.

\section{Giriș}

Ülkemizde sanayileşme ve teknolojinin hızla gelişmesi ile birlikte hızlı nüfus artışı, su, hava ve toprak kirlenmesini beraberinde getirmekte, çevre kirliliği insan yaşamını tehdit eden boyutlara ulaşmaktadır. Günümüze gelinceye kadar tarımsal alanlarda uygulanan N-P-K ile sağlanan ürün artışı, topraklardan sömürülen iz element miktarlarını da artırmaktadır. $\mathrm{Bu}$ aşırı sömürme sonucu topraklar, artık bitkilerin iz element gereksinimini karşılayamaz duruma gelebilmektedir. Ayrıca özellikle sürekli olarak fosforlu ve kalsiyumlu gübre kullanımı sonucu, topraktaki kimi iz elementlerin yararlılığı azalabilmektedir. Topraklar, metaller bakımından biyolojik dolanımın sadece bir parçasıdır. Aynı zamanda topraklar, bu bileşiklerin büyük miktarlarının son depolama bölgesidir. Kirlenmeye maruz kalmış toprağı, doğal haline getirmek ekonomik ve teknik açıdan zordur. Bunu önlemek için kirlilik potansiyeli olan kaynakların zamanında belirlenmesi ve önleyici tedbirlerin alınması gerekmektedir.

Kontamine bölgelerde genellikle $\mathrm{Pb}, \mathrm{Cr}, \mathrm{As}, \mathrm{Zn}, \mathrm{Cd}, \mathrm{Cu}$ ve $\mathrm{Hg}$ gibi toksik metaller bulunur. $\mathrm{Bu}$ metaller, besin zincirinde biyoakümülasyon ve biyomagnifikasyon gibi risklerinden dolayı bitki üretimini azaltırlar, bu yüzden üzerinde önemle durulması gereken çevresel kirleticiler arasındadırlar [1]. Toprağın ağır metaller ile kirlenmesi insanlara ve ekosisteme tehlike oluşturabilir. Kirlenmiş toprak, besin zinciri (toprak bitki-insan veya toprak bitki-hayvan-insan) yoluyla doğrudan yutulması veya teması, 
kirlenmiş yeraltı suyunun içilmesi, Fitotoksisite sonucu gıda kalitesinde azalma, tarımsal üretimin arazi kullanılabilirliğini azaltması gibi problemleri beraberinde getirir [2-4]. Toprağa karışan ağır/toksik metaller insanlar için de tehlikeli olabilmektedir. Bugün en çok yaygınlık gösteren hastalıklar için toksik çevresel kirleticiler suçlanmaktadır [5]. Çeşitli endüstriyel faaliyetler sonucunda açığa çıkan atıksular, katı atıklar ve havaya salınan emisyonlar doğrudan ya da dolaylı olarak toprağ etkilemektedir [6,7].

Bu çalışmada Trakyanın endüstriyel açıdan en yoğun olduğu Çorlu ilçesinde endüstriyel atıksuların deşarj noktalarına yakın topraklarında seçilmiş ağır metallerin $(\mathrm{Pb}, \mathrm{Cu}, \mathrm{Zn}$, $\mathrm{Fe}, \mathrm{Mn}, \mathrm{Ni}, \mathrm{Co}, \mathrm{Cd}$ ve $\mathrm{Cr}$ ) konsantrasyonlarının izlenmesi ve değerlendirilmesi yapılmıştır. $\mathrm{Bu}$ çalışmanın ve bölgede yapılmış diğer ağır metal çalışmalarının sonuçları ağır metal kirliliği kontrolü için yerel yönetimler tarafından kullanılabilecektir.

\section{Materyal metod}

\section{1. Çalışma alanı}

Istranca Dağlarındaki Ergene kaynaklarından doğan Ergene Nehri, uluslararası su niteliğinde olan Meriç Nehrinin bir kolu olup Trakya'nın kuzeydoğusundan ve Ergene deresi adıyla kuzeydoğu ve güneybatı istikametinde akmaktadır. İnanlı Köyü civarında doğudan gelen Çorlu Deresi ile birleşerek Ergene Nehri ismini almaktadır. Ergene Nehrinin en önemli kollarından biri olan Çorlu Deresi; Çerkezköy, Çorlu ve Muratlı İlçeleri sınırları dahilinde ki değişik sektörlere ait sanayi kuruluşlarının evsel ve endüstriyel atık sularını toplamaktadır. Tekirdağ ili sanayinin yoğun olduğu bölgelerden biri olduğundan kirletici unsurlarla iç içedir. Sanayi açısında en yoğun alanlar; Çorlu-Velimeşe, Veliköy-Çerkezköy; Çorlu-Marmaracık-Ulaş; VakıflarMisinli-Büyükkarıştıran; Çorlu, Türkgücü köyü; Muratlı-Büyükkarıştıran arasıdır [8]. Çorlu'da sanayi açısından yoğun olan kritik noktalara göre numune alma noktaları tespit edilmiştir (Şekil 1).

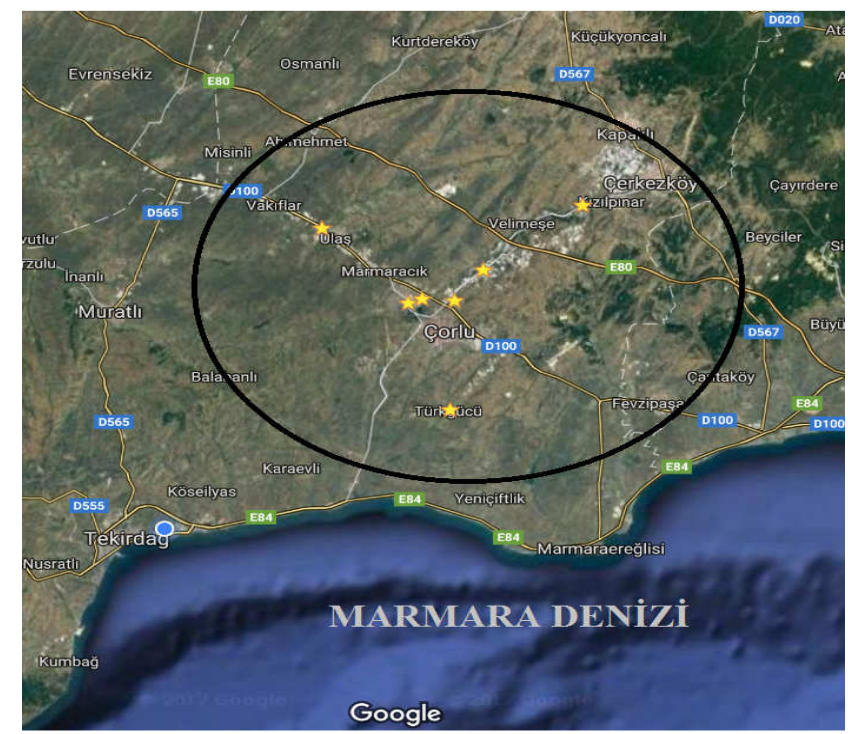

Şekil 1. Toprak numunelerinin toplandığı bölge. 


\subsection{Metod}

Belirlenen 7 noktadan toplanan toprak numuneleri (Tablo 1) laboratuvarda doğal ortamda kurutulduktan sonra $110^{\circ} \mathrm{C}$ de 24 saat etüvde sabit tartıma getirilmiștir. Numunelerin analize hazırlanmasında EPA 3051 Metodu kullanılmıştır. Ekstraksiyon için $0.5 \mathrm{~g}$ toprak numunesi tartılarak üzerine $6 \mathrm{ml} \mathrm{HCl}$ ve $3 \mathrm{ml} \mathrm{HNO}{ }_{3}$ eklenmiştir. $\mathrm{Bu}$ karışım mikrodalga fırında (Mileston MLS 1200), $180{ }^{\circ} \mathrm{C}$ de $30 \mathrm{dk}$ bekletilerek ekstraksiyon işlemi uygulanmıştır. Mikrodalga fırından alınan çözeltiler saf su ile 50 ml'ye tamamlanarak FAAS (Thermo Electron Corporation S Series) de ağır metal tayini yapılmıştır.

Tablo 1. Toprak numunelerinin toplandığı noktalar

\begin{tabular}{cc}
\hline Numune noktaları & Numune toplama alanları \\
\hline T1 & Unilever, Ergene Nehri civarı \\
T2 & Velimeşe, Çorlu Deresi civarı \\
T3 & Sinandede Deresi civarı \\
T4 & Çorlu-Sinandede Birleşimi civarı \\
T5 & Türkgücü köyü \\
T6 & Sinop Mah, Çorlu Deresi civarı \\
T7 & Velimeşe Çerkezköy OSB \\
\hline
\end{tabular}

\subsection{Korelasyon analizi}

Kirlilik kaynaklarını belirlemek için korelasyon analizi yapılarak [9] veriler Windows SPSS 12.0 programına uyarlanmıştır [10]

\section{Bulgular}

Sanayinin yoğun olduğu Çorlu ilçesinin farklı bölgelerinden belirli periyotlarda toplanan toprak numunelerinde ağır metal içeriklerinde değişken sonuçlar tespit edilmiştir. Referans değerler, tanımlayıcı istatistik ve ölçüm sonuçları Tablo 2'de verilmiştir. Toprak numunelerinin $\mathrm{pH}$ değerleri 7.0 ile 7.7 arasında değişmiştir ve tüm noktalarda önemli bir farklılık göstermemiștir. Toplanan periyotlara göre toprak numunelerindeki $\mathrm{Pb}$ ve $\mathrm{Cu}$ içeriği numunelerin tamamında TKKY EK-Ia' ya göre sınır değerlerin altında tespit edilmiştir. T2 noktasından alınan numunelerde $\mathrm{Cr}, \mathrm{Zn}$ ve $\mathrm{Cd}$ miktarı TKKY EK-Ia'ya göre bazı aylarda sınırların üzerinde tespit edilmiştir. T3 noktasından alınan numunelerde Cr miktarı TKKY EK-Ia' ya göre Temmuz 2006' da sınır değerin üzerinde tespit edilmiştir. T4 noktasından alınan numunelerde $\mathrm{Zn}$ ve $\mathrm{Cd}$ miktarı TKKY EK-Ia'ya göre sınır değerin üzerinde tespit edilmiştir. T5 noktasından alınan numunelerde $\mathrm{Cr}$, Zn ve Ni miktarı TKKY EK-Ia'ya göre sınır değerin üzerinde tespit edilmiştir. T6 ve T7 noktalarından alınan numunelerde $\mathrm{Zn}, \mathrm{Ni}, \mathrm{Cr}$ ve $\mathrm{Cd}$ miktarı TKKY EK-Ia’ ya göre sınır değerin üzerinde tespit edilmiştir. 
Tablo 2. Çalışma alanında toprak numunelerinde ağır metal konsantrasyonları ( $\mathrm{mgkg}^{-1}$ dry soil).

\begin{tabular}{|c|c|c|c|c|c|c|c|c|c|c|}
\hline & \multicolumn{10}{|c|}{ Ăğı metal konsantrasyonları (mgkg $\left.{ }^{-1}\right)$} \\
\hline $\begin{array}{l}\text { Numune } \\
\text { noktaları }\end{array}$ & $\mathbf{p H}$ & $\mathbf{P b}$ & $\mathrm{Cr}$ & $\mathbf{Z n}$ & $\mathbf{F e}$ & Mn & $\mathbf{C u}$ & $\mathbf{N i}$ & Cd & Co \\
\hline \multicolumn{11}{|l|}{ Tem.06 } \\
\hline T2 & 7.0 & TE. & 123.54 & 151.84 & 4377,43 & 755.73 & 3.38 & 26.68 & 0.19 & 8.44 \\
\hline T3 & 7.2 & TE. & 72.06 & TE. & 3005,78 & TE. & TE. & 9.79 & 0.11 & 3.40 \\
\hline T5 & 7.0 & TE. & 191.96 & 1170.05 & 8636,36 & 652.27 & 13.54 & 86.88 & 0.79 & 7.58 \\
\hline \multicolumn{11}{|l|}{ Eki.06 } \\
\hline T3 & 7.1 & TE. & 14.99 & 148.25 & 45,11 & 458.37 & TE. & 23.55 & 0.18 & 7.57 \\
\hline T4 & 7.4 & TE. & 22.66 & 868.51 & 76,45 & TE. & 6.66 & 42.60 & 0.39 & 7.39 \\
\hline T5 & 7.3 & TE. & 664.83 & 355.62 & TE. & 181.12 & 7.03 & 45.08 & 0.49 & 9.59 \\
\hline T6 & 7.1 & TE. & 13.82 & 520.47 & 3240,55 & TE. & TE. & 37.14 & 0.08 & 7.21 \\
\hline \multicolumn{11}{|l|}{ Oca.07 } \\
\hline T1 & 7.4 & 7.03 & 24,66 & TE. & 4800.61 & TE. & 2,9 & 54,35 & 0,67 & 9.05 \\
\hline $\mathbf{T} 2$ & 7.2 & TE. & 21.67 & 3.37 & 4413.51 & TE. & TE. & 42,89 & 0,5 & 10.31 \\
\hline T3 & 7.3 & 22.72 & 13.25 & 44.04 & 2464.64 & TE. & TE. & 18,91 & 0,76 & 8.11 \\
\hline T4 & 7.0 & 15.23 & 24.5 & 309.56 & 3784.86 & TE. & TE. & 27,55 & 0,64 & 7.07 \\
\hline T5 & 7.2 & 6.52 & 32.65 & 2034.37 & 7500 & TE. & TE. & 86,07 & 1,47 & 18 \\
\hline T6 & 7.6 & 8.99 & 27.30 & 982.43 & 6409.26 & TE. & 13,23 & 61,46 & 0,72 & 14.43 \\
\hline T7 & 7.1 & TE. & 129.55 & 282.77 & 5742.57 & TE. & TE. & 62,99 & TE. & 3.14 \\
\hline \multicolumn{11}{|l|}{ Nis.07 } \\
\hline T1 & 7.3 & TE. & 11.33 & 8.47 & TE. & 110.06 & TE. & 0.02 & 0.05 & 1.03 \\
\hline $\mathbf{T} 2$ & 7.6 & 34.49 & 37.72 & 42.94 & TE. & 730.28 & TE. & 11.54 & 0.20 & 11.55 \\
\hline T4 & 7.2 & 35.55 & 37.52 & 102.54 & TE. & 457.92 & 4.07 & 12.75 & 0.22 & 18.36 \\
\hline T5 & 7.5 & 24.31 & 37.71 & 43.90 & TE. & 313.38 & 1.40 & 40.68 & 0.17 & 18.55 \\
\hline T6 & 7.2 & 13.26 & 54.86 & 99.43 & 12142 & 606.12 & 48,08 & 53.43 & 4.34 & 13.61 \\
\hline \multicolumn{11}{|l|}{ Eki.07 } \\
\hline T1 & 7.7 & 20.42 & 89.86 & 103.55 & 6214 & 701.28 & 7.95 & 63.42 & 3.05 & 1.55 \\
\hline $\mathbf{T} 2$ & 7.1 & TE. & TE. & 24.50 & 5834 & 7428.46 & 4.61 & 28.28 & 5.45 & 11.70 \\
\hline T3 & 7.0 & 20.74 & TE. & 2.87 & 5248 & 521.84 & 1.20 & 1.56 & 2.38 & 2.29 \\
\hline T4 & 7.2 & 33.73 & 38.13 & 22.02 & 1826 & 525.41 & 0.68 & 3.46 & 3.33 & 1.17 \\
\hline T5 & 7.4 & TE. & 67.37 & 34.92 & 208 & 570.92 & 13.74 & 63.63 & 0.31 & 1.28 \\
\hline T6 & 7.1 & 9.75 & 67.44 & 52.23 & 1446 & 610.59 & 15.23 & 46.91 & 3.01 & 11.06 \\
\hline T7 & 7.2 & 20.85 & TE. & 2.78 & 8741 & 125.21 & 3.83 & TE. & 7.46 & TE. \\
\hline Ortalama & 7.2 & 10.52 & 69.97 & 285.05 & 3846.24 & 567.26 & 5.67 & 36.60 & 1.42 & 8.20 \\
\hline $\begin{array}{l}\text { Standart } \\
\text { sapma }\end{array}$ & & 12.29 & 129.51 & 480.6 & 3330.25 & 1428.70 & 9.93 & 25.50 & 1.92 & 5.51 \\
\hline$[11]$ & & 30 & 73 & 192 & & & 41 & 43 & 0,3 & \\
\hline [12] & & 100 & 100 & 300 & & & 100 & 100 & 5 & 50 \\
\hline [13] & & 300 & & 300 & & & 140 & 75 & 3 & \\
\hline [14] & & 70 & 60 & 150 & & & 50 & 50 & 1 & \\
\hline
\end{tabular}

TE: Tespit edilemedi 
Özellikle Türkgücü köyü, Çorlu deresi (Sinop Mah.) ve Velimeşe Çerkezköy OSB civarından toplanan toprak numunelerinde $\mathrm{Zn}, \mathrm{Cr}, \mathrm{Cd}$ ve Ni içeriği çoğunlukla TKKY EK-Ia'da belirtilen sınır değerlerin üzerinde tespit edilmiştir [15-20]. Bu sonuçlara göre, bölgede tekstil sanayi, deri sanayi, kum-taş-stabilize çakıl ocağı, gıda sanayi, kimya sanayi, inşaat sanayi, otomotiv sanayi, tuğla sanayi, kağıt sanayi, mezbahalar, organize arıtma tesisi gibi endüstriyel faaliyetlerin yoğunluğu düşünülerek kaynak ve kirlilik tespiti odaklı projelere ihtiyaç olduğu aşikardır.

\section{1. Ăgır metallerin kirlilik kaynakları}

Toprak numunelerinde metaller arasında ilişkiyi göstermek için korelasyon analizi yapıldı ve korelasyon matrisi Tablo 3'de gösterildi. $\mathrm{Pb}$ ve Ni arasında negatif yönde anlamlı bir ilişki tespit edildi. $\mathrm{Zn}$ ve $\mathrm{Ni}$ arasında; $\mathrm{Fe}$ ve $\mathrm{Cu}$ arasında; $\mathrm{Fe}$ ve $\mathrm{Cd}$ arasında; $\mathrm{Mn}$ ve $\mathrm{Cd}$ arasında pozitif yönde güçlü anlamlı bir ilişki tespit edildi. Ağır metaller arasındaki korelasyon, onların kaynaklarını yorumlamak için kullanılabilir [21, 22]. Toprakta ağır metaller arasında yüksek oranda pozitif korelasyon bu ağır metallerin benzer kirlilik kaynaklarına sahip olduğunu akla getirebilir.

Tablo 3. Metallerin konsantrasyonları arasında korelasyon analizi

\begin{tabular}{|c|c|c|c|c|c|c|c|c|c|c|}
\hline & & $\mathrm{Pb}$ & $\mathrm{Cr}$ & $\mathrm{Zn}$ & $\mathrm{Fe}$ & $\mathrm{Mn}$ & $\mathrm{Cu}$ & $\mathrm{Ni}$ & $\mathrm{Cd}$ & $\mathrm{Co}$ \\
\hline \multirow[t]{3}{*}{$\mathrm{Pb}$} & Pearson Correlation & 1 &,- 246 &,- 265 &,- 146 &,- 106 &,- 052 &,$- 411^{*}$ &, 244 &, 157 \\
\hline & Sig. (2-tailed) & &, 226 &, 190 &, 487 &, 605 &, 802 &, 037 &, 230 &, 445 \\
\hline & $\mathrm{N}$ & 26 & 26 & 26 & 25 & 26 & 26 & 26 & 26 & 26 \\
\hline \multirow[t]{3}{*}{$\mathrm{Cr}$} & Pearson Correlation &,- 246 & 1 & ,101 &, 252 &,- 093 & , 108 &, 247 &,- 170 &, 016 \\
\hline & Sig. (2-tailed) &, 226 & &, 624 &, 225 &, 650 &, 600 & ,224 &, 406 &, 940 \\
\hline & $\mathrm{N}$ & 26 & 26 & 26 & 25 & 26 & 26 & 26 & 26 & 26 \\
\hline \multirow[t]{3}{*}{$\mathrm{Zn}$} & Pearson Correlation &,- 265 &, 101 & 1 &, 307 &,- 158 &, 026 &, $633^{k *}$ &,- 168 & ,361 \\
\hline & Sig. (2-tailed) &, 190 &, 624 & &, 136 &, 439 &, 901 &, 001 &, 412 & .070 \\
\hline & $\mathrm{N}$ & 26 & 26 & 26 & 25 & 26 & 26 & 26 & 26 & 26 \\
\hline \multirow[t]{3}{*}{$\mathrm{Fe}$} & Pearson Correlation &,- 146 &, 252 &, 307 & 1 &, 118 &, $512^{* *}$ &, $405^{*}$ &, $545^{* *}$ & 017 \\
\hline & Sig. (2-tailed) &, 487 &, 225 &, 136 & &, 573 &, 009 &, 045 &, 005 &, 936 \\
\hline & $\mathrm{N}$ & 25 & 25 & 25 & 25 & 25 & 25 & 25 & 25 & 25 \\
\hline \multirow[t]{3}{*}{$\mathrm{Mn}$} & Pearson Correlation &,- 106 &,- 093 &,- 158 & ,118 & 1 &, 053 &,- 069 & $.457^{*}$ &, 121 \\
\hline & Sig. (2-tailed) &, 605 &, 650 &, 439 &, 573 & &, 797 &, 739 &, 019 &, 557 \\
\hline & $\mathrm{N}$ & 26 & 26 & 26 & 25 & 26 & 26 & 26 & 26 & 26 \\
\hline \multirow[t]{3}{*}{$\mathrm{Cu}$} & Pearson Correlation &,- 052 & ,108 &, 026 &, $512^{\text {thn }}$ & .053 & 1 & ,369 &, 338 & , 192 \\
\hline & Sig. (2-tailed) &, 802 &, 600 & ,901 & ,009 &, 797 & &, 064 &, 091 & ,346 \\
\hline & $\mathrm{N}$ & 26 & 26 & 26 & 25 & 26 & 26 & 26 & 26 & 26 \\
\hline \multirow[t]{3}{*}{$\mathrm{Ni}$} & Pearson Correlation &,$- 411^{*}$ & ,247 & $.633^{* 3}$ &, $405^{*}$ &,- 069 & .369 & 1 &,- 166 &, 313 \\
\hline & Sig. (2-tailed) &, 037 &, 224 &, 001 &, 045 &, 739 &, 064 & &, 417 &, 120 \\
\hline & $\mathrm{N}$ & 26 & 26 & 26 & 25 & 26 & 26 & 26 & 26 & 26 \\
\hline \multirow[t]{3}{*}{$\mathrm{Cd}$} & Pearson Correlation &, 244 &,- 170 &,- 168 &, $545^{* *}$ & $.457^{*}$ &, 338 &,- 166 & 1 &,- 177 \\
\hline & Sig. (2-tailed) &, 230 &, 406 &, 412 &, 005 &, 019 & .091 &, 417 & &, 386 \\
\hline & $\mathrm{N}$ & 26 & 26 & 26 & 25 & 26 & 26 & 26 & 26 & 26 \\
\hline \multirow[t]{3}{*}{ Co } & Pearson Correlation & , 157 &, 016 &, 361 &, 017 & ,121 & ,192 &, 313 &,- 177 & 1 \\
\hline & Sig. (2-tailed) &, 445 &, 940 &, 070 & ,936 &, 557 &, 346 & , 120 &, 386 & \\
\hline & $\mathrm{N}$ & 26 & 26 & 26 & 25 & 26 & 26 & 26 & 26 & 26 \\
\hline
\end{tabular}

*Correlation is significant at the 0.05 level ; **Correlation is significant at the 0.01 level. 


\section{Tartışma ve sonuç}

Yapılan toprak analizleri sonucunda, farklı numune alma zamanlarında birbirinden farklı sonuçlar elde edilmiştir. Seçilmiş bölgelerin toprağındaki farklı ağır metallerin, atıksuların deşarjı ile kontamine olmuş yüzey ve yeraltı suları ile sulamadan kaynaklandığı düşünülmektedir. Bu nedenle atıksu arıtma teknolojileri, insan sağlığ için risk oluşturan ağır metallerin giderimi proseslerini de içermelidir. Topraklar, metaller bakımından biyolojik dolanımın sadece bir parçasıdır. Aynı zamanda topraklar, bu bileşiklerin büyük miktarlarının son depolama bölgesidir [22]. Kirlenmeye maruz kalmış toprağı, doğal haline getirmek ekonomik ve teknik açıdan zordur. Bunu önlemek için kirlilik potansiyeli olan kaynakların zamanında belirlenmesi ve önleyici tedbirlerin alınması gerekmektedir.

\section{Teșekkür}

Bu çalışma Trakya Üniversitesi Bilimsel Araştırmalar Birimi tarafından desteklenmiştir (TÜBAP 720).

\section{Kaynaklar}

[1] Rajeswari, R, ve Sailaja, N., Impact of heavy metals on environmental pollution, Journal of Chemical and Pharmaceutical Sciences, 3,175, (2014).

[2] McLaughlin M. J., Zarcinas B. A., Stevens D. P., ve Cook, N., Soil testing for heavy metals, Communications in Soil Science and Plant Analysis, 31, 11-14, 1661-1700, (2000).

[3] McLaughlin, M. J., Hamon, R. E., McLaren, R. G., Speir, T. W., ve Rogers, S. L, Review: a bioavailability-based rationale for controlling metal and metalloid contamination of agricultural land in Australia and New Zealand, Australian Journal of Soil Research, 38, 6, 1037-1086, (2000).

[4] Ling, W, Shen, Q, Gao, Y, Gu, X, and Yang, Z., Use of bentonite to control the release of copper from contaminated soils, Australian Journal of Soil Research, 45, 8, 618-623, (2007).

[5] United States Department of Agriculture, National Resources Conservation Service, Soil Quality Institute, Heavy metal soil contamination, Soil Quaity-Urban Technical, Note No 3., 411, 36832, 334-844-4741, X-177, (2000).

[6] Li F.Y., Fan Zh. P., Xiao P. F., Oh K., Ma X. P., ve Hou W. Contamination, chemical speciation and vertical distribution of heavy metals in soils of an old and large industrial zone in Northeast China. Environmental Geology, 57, 18151823, (2009).

[7] Li J. L., He M., Han W., and Gu Y. F., Analysis and assessment on heavy metal sources in the coastal soils developed from alluvial deposits using multivariate statistical methods. Journal of Hazardous Materials, 164, 976-981, (2009).

[8] TC Çevre ve Şehircilik Bakanlığı ,Tekirdağ Valiliği Çevre ve Şehircilik İl Müdürlüğü, Su Kirliliği. http://www.csb.gov.tr/iller/tekirdag/index.php?Sayfa= sayfa\&Tur= webmenu\&Id=4341 (22.06.2017).

[9] Guo P., Xie ZL., Li J., Kang CL., and Liu JH., Relationships between fractionations of $\mathrm{Pb}, \mathrm{Cd}, \mathrm{Cu}, \mathrm{Zn}$ and $\mathrm{Ni}$ and soil properties in urban soils of Changchun, China, Chinese Geographical Science, 15, 179-185, (2005). 
[10] Liao, F., Zhou, S., Zhang, H., Wu, S., and Zhao, Q., Spatial distribution and changes of heavy metals of agricultural lands in typical pregrading coast in Dongtai City, Jiangsu province, China, Chinese Geographical Science, 18, 276283 (2008).

[11] Pérez C., Martínez M.J., Vidal J., and Navarro C., Proposed reference values for heavy metals in calcaric fluvisols of the Huerta de Murcia (SE Spain).In: Sustainable use and management of soils in arid and semi arid regions (Fáz A., Ortiz R., Mermut A.R., eds). Quaderna Editorial, Cartagena, Murcia, Spain, 495-496, 2002.

[12] Kabata-Pendias A., and Pendias H., Trace elements in soils and plants. 3rd edition. CRC Press, Boca Raton, Florida, 413, (2001).

[13] CEC, Council Directive of 12 June 1986 on the protection of the environment, and in particular of the soil, when sewage sludge is used in agriculture. Official Journal of the European Communities, L181, 6-12, (1986).

[14] Soil Pollution Prevention Regulation. Turkish Ministry of Environment and Forestry, Ankara, Turkey, (2005).

[15] Sabudak, T., Seren, G., Kaykioglu G., and Dincer AR, Determination of trace elements in soil and sunflower (Helianthus annuus L.) plant parts, Fresenius Environmental Bulletin, 16,10,1274-1278, (2007).

[16] Fabis W., Schadstaftbelastung von Bödn-auswirkurgen auf Böden-und wasserqalitat Allg Forstzeitsehr. Munich: BLV Verloggsellshaft, (1987).

[17] Tembo BD, Scihilongo K., Cernak J. Distiribution of copper, lead,cadmium and zinc concentrations in soil around Kabwe town in Zambia, Chemosphere, 63, 497-501, (2006).

[18] Sezgin N., Özcan HK., Demir G., Nemlioğlu, and Bayat C., Determination of heavy metal concentartions in street dusts in İstanbul E-5 highway, Environmental International, 29, 979-985, (2003).

[19] Adiloğlu A., Adiloğlu S., Bellitürk K., Karakaş Ö., Sümer A., Gönülsüz E., and Sari H., Tekirdağ ili kıyı ş̧eridi topraklarında ağır metal kirliliği. 1. Kıyı Bölgelerinde Çevre Kirliliği ve Kontrolu Sempozyumu, Tekirdag, 351-365, (2011).

[20] Anyakora, C., Ehianeta, T., and Umukoro, O., Heavy metal levels in soil samples from highly industrialized Lagos environment, African Journal of Environmental Science and Technology, 7, 9, 917-924, (2013).

[21] Hu, B., Zhou, j., Liu, 1., Meng, W., ve Wang, Z., Assessment of heavy metal pollution and potential ecological risk in soils of tianjin sewage irrigation region, north china, Journal of Environmental\&Analytical Toxicology, 7, 1, (2017).

[22] Mtunzi, F. M., Dikio1, E. D., ve Moja, S. J., Evaluation of heavy metal pollution on soil in Vaderbijlpark, South Africa, International Journal of Environmental Monitoring and Analysis , 3, 2, 44-49, (2015).

[23] Haktanır, K., Çevre Kirliliği, Ankara Üniversitesi Ziraat Fakültesi Ders Notu. 107,82-83(1983). 